\title{
Editorial:
}

\section{A Psychology of Aging: Who Needs It?}

Almost every year at the annual meeting of the Canadian Association on Gerontology (CAG), the small crowd at the Psychology Division luncheon holds an informal referendum: Should we remain.separate or become part of a larger division within CAG such as Social Sciences? Despite the fact that many around the table work in multidisiplinary teams or departments, we always arrive at the same point in these discussions. Psychology needs an identifiable presence through its own division. Why?

Trent University sociologist, Stephen Katz, in his book, The Disciplining of Old Age (1996) argues, following Foucault, that disciplines construct dominant representations of the world, and also "determine the ways in which the people who inhabit it can be known, studied, calculated, trained, helped, punished, and liberated" (p. 2). One could argue that "geropsychologists" are doubly guilty of constraining knowledge, first through their decision to separate old age from the rest of the life-span, and second through turning a uniquely psychological lens on the issues that emerge from a look at older persons. Certainly, a glance at scholarly articles on the psychology of aging reveals some quite esoteric material: for example, age effects on saccadic eye movements, negative priming, and emotional selectivity. This material does not easily become nomadic, that is, migrate to other age groups or disciplines. So perhaps Katz is right. Disciplinarity constrains what may be considered valid and real areas of study, and gets in the way of an open and critical look at the assumptions behind these areas.

Before we blend psychology into the rest of the social and biological sciences, however, let us consider its contribution to our understanding of aging. Psychologists have long been interested in how people develop over the course of their lives. Early developmentalists focussed on childhood, a period of rapid, generally progressive, change. These researchers found the organismic approach of Piaget useful in understanding a period of life where biology had such a clear and powerful impact on development. As more and more of these researchers attempted to apply the same thinking to the adult years, however, they realized the limitations of an organismic perspective. Organicism seemed to push them right into the arms of the waiting biodecremental camp: once psychological and physical growth are "achieved" in early adulthood, then surely both must decline in equal harmony as part of the aging process.

Psychologists were not too happy with the idea that all they could look forward to, by the time they finally got their doctorates, was a downhill

Canadian Journal on Aging / La Revue canadienne du vieillissement / Vol. 17 no. 4 1998, i-xi 
slide in functioning. Advanced age left them even more irritated with this view (e.g., Skinner, 1983). Perhaps this is why Paul Baltes' (e.g., 1987) life-span developmental approach had such immediate appeal. Baltes theorized that development occurred in context, over the life-span, and could be progressive or regressive. It was possible, then, to see psychological aging as firmly embedded in a social context. Researchers were encouraged to go beyond, for example, the observation that declines in working memory are common in the second half of the life-span, to an understanding that such decline is by no means universal, and is heavily influenced by individual biography and environment.

This view clearly would have pleased B.F. Skinner who, in his 1983 American Psychologist article on coping with his own aging, urged researchers to dispense with the horticultural metaphor of aging - i.e. rot and decay - and realize that "Much of what seems to be the unfolding of an inner potential [with development] is the product of an unfolding environment: a person's world develops" (p. 239). Following this line of thinking, Skinner suggested that practitioners should spend more time thinking about "prosthetic environments," that is, environments which provide older people with a wide range of experiences and cognitive stimulation. These enriched environments would mitigate against the changed contingencies of reinforcement that produce boredom and lack of interest in old age. If life no longer provides sufficient incentives - because of job loss, inattention from one's children, or restricted social networks declines in functioning are almost inevitable.

Skinner's views were prototypically mechanistic and many psychologists are rather embarrassed if they must admit to admiring them. Nevertheless, threads of his theorizing seem deeply woven into current contextual thinking on the psychology of aging. A promising theory arising out of Baltes' life-span developmental framework - selective optimization with compensation - puts particular emphasis on micro and macro environmental effects on development (Baltes, 1997). The first component of this framework, selection, refers to the choices that individuals make either consciously or unconsciously - to focus on domains of personal development in which they are likely to be successful (e.g., playing chess instead of tennis). The second, optimization, refers to maintaining skills or competencies which have already been acquired (e.g., daily practice of the Bach cello concertos learned in one's youth). The third, compensation, refers to efforts that an individual makes to maintain competencies when losses have occurred, goals have become incompatible or new constraints have been imposed (e.g., seeking out a new confidant after widowhood). This approach acknowledges possible aging-related losses or restrictions, but points to the control an older person has in making changes and choices to maximize functioning within current circumstances.

As I have noted elsewhere (Pratt \& Norris, in press), selective optimization with compensation provides an explicit model for conceptualizing 
"successful aging". How older adults age successfully is becoming a central concern for psychological practitioners and researchers alike. Perhaps partly because of our own experiences and hopes for the future, we seem determined to uncover the "secrets" of aging well. On the eve of the International Year of Older Persons, this seems a fitting mission. We are surrounded by possible prototypes of successful agers. For example, the United Nations Secretary-General Kofi Annan - himself 60 years old hailed born-again astronaut, John Glenn, as "a pioneer in longevity" before his October trip into space (Reuters, 1998). The U.N. Non-governmental Committee on Aging went further in calling Glenn "not only a role model for those of us in our higher years, [but] a role model for all generations".

At least one Gen-Xer (Foust, 1998) has questioned the value of highlighting the stories of people like John Glenn. He notes that the real business of aging research gets lost in the glamour of a media event and the nostalgia of people old enough to remember the Mercury launch of 1962. This observation prompts gerontologists to take a close look at our work and our traditions as we attempt to understand new developments. A few years ago, my colleague, Michael Pratt and I (Pratt \& Norris, 1994) attempted to do this through an analysis of research on the psychology of aging. We found that existing research was derived from one of four conceptual perspectives: psychometric, information processing, developmental and social psychological. We noted that the choice of perspective was strongly affected by the phenomenon under study, and that no single perspective could be seen as "best" or even most promising in a broad, programmatic sense. We stressed the importance of using some theoretical framework, however, to move us beyond descriptions of aging-related phenomena into meaningful explanation.

This issue of the Canadian Journal on Aging combines the best in the use of these traditional approaches to the psychology of aging with a vigorous attempt at uncovering the meaning of successful aging in a variety of contexts. Bouchard and colleagues' paper, "Psychometric Properties of the French Version of the State-Trait Anxiety Inventory (form Y) Adapted for Older Adults" and Laprise and Vézina's article, "Diagnostic Performance of the Geriatric Depression Scale and the Beck Depression Inventory with Nursing Home Residents," fit within the psychometric tradition in psychology. These papers, with their use of standardized tests and highly controlled conditions, contribute to an understanding of individual differences in the aging experience. As well as advancing our ability to measure important psychological constructs such as anxiety and depression, they encourage us to examine our definitions of these constructs within the context of later life, and of two languages and cultures.

Landreville and Guérette's article, "Psychometric Properties of a Modified Version of the Treatment Evaluation Inventory for Assessing the Acceptability of Treatments for Geriatric Depression" also draws from the psychometric tradition, but is strongly influenced, as well, by work in social 
psychology on perceptions. O'Rourke and Wenaus's study, 'Marital Aggrandizement as a Mediator of Burden Among Spouses of Suspected Dementia Patients" weaves threads from several areas in social psychology - coping, social exchange, and reconstruction of memories - to explore an important mediator of burden in spouses, that of the tendency to idealize the partner and the relationship. Fox and Gooding's research, "Physical Mobility and Social Integration: Their Relationship to the Well-Being of Older Canadians," takes a social psychological stance in its consideration of the importance of social connectedness. These three articles illustrate the usefulness of the methodological and theoretical eclecticism of social psychology.

Patrick and Howell's article, "Mental Status and Self-Medication Ability in the Hospitalized Elderly," draws upon work within information processing, considering the impact of cognitive deficits on the ability to maximize functioning in one important activity of daily living. This study is an important reminder that success in old age is not restricted to the John Glenns of this world. Even cognitively frail older adults can maintain competencies which bolster self-esteem and facilitate optimization in other areas of their lives.

Finally, Doucet and colleagues' paper, "Thèmes d'inquiétudes et tendance à s'inquiéter chez les ainés" draws from several traditions: information processing, social psychology, and developmental. One of the most significant findings in this study was the identification of old-old as a group worthy of further, targetted, study. As Baltes (1997) has also noted, "The oldest old are not simply individuals who continue to stay alive because their functional status remains at the same level as that of the younger old" (p. 376). Their success at aging may be both instructive to others, and unique to their developmental stage.

Research on aging is itself at an awkward developmental stage. As Katz (1996) noted, "old age is caught between the efforts to discipline, calculate, and manage it and the forces that undiscipline, diversify, and fragment it" (p. 139). I would argue, however, from my perspective as a life-span developmentalist, that this dialectic is an inherent characteristic of the growth of our understanding. And it is not just the province of psychologists. Gerontologists, whatever their disciplinary allegiance, can advance the study of aging through specialized knowledge, unique questions, and the motivation to understand what it means to age well. A well-defined and strong sense of identity, as psychologists know, is important to healthy functioning. As well, we can all remain open to influences from each other that disrupt our hard-won understandings and force us to reconceptualize our questions and ourselves. Exposure to diverse social relationships, attitudes, and beliefs, as psychologists know, promotes cognitive complexity. So, I would answer to my colleagues who wonder whether they should keep their disciplinary boundaries intact: that there is value in doing this, but only if you cross those boundaries for lunch occasionally. 


\section{References}

Baltes, P.B. (1987). Theoretical propositions of life-span developmental psychology: On the dynamics between growth and decline. Developmental Psychology, 23, $611-626$.

Baltes, P.B. (1997). On the incomplete architecture of human ontogeny: Selection, optimization, and compensation as foundations of developmental theory. American Psychologist, 52, 366-380.

Foust, J. (1998, November 1). Glenn again, for the very first time: A Gen-X perspective on STS-95. [On-line]. Available:www.spaceviews.com/features/ glenn/glenn-genx.html.

Katz, S. (1996). Disciplining old age: The formation of gerontological knowledge. Charlottesville \& London: University Press of Virginia.

Pratt, M.A., \& Norris, J.E. (in press). Moral Development in Maturity: Lifespan Perspectives on the Processes of Successful Aging. In T. Hess \& F. BlanchardFields, Social Cognition and Aging. New York: Academic Press.

Pratt, M.A., \& Norris, J.E. (1994). The social psychology of aging: A cognitive perspective. Oxford: Blackwell.

Reuters. (1998, October 30). U.N. lauds Glenn as "Pioneer for longevity". [On-line]. Available: www.cnn.com/TECH/space/9810/30/un.glen.reut.

Skinner, B.F. (1983). Intellectual self-management in old age. American Psychologist, 38(3), 239-244.

Joan E. Norris 